\title{
СПРАВЕДЛИВАЯ ВОЙНА РУКАМИ ЧАСТНИКА: «ПРИВАТИЗАЦИЯ» ВОЕННЫХ ДЕЙСТВИЙ НА МОРЕ В АНГЛИИ В 1585-1603 гГ.
}

К концу правления Тюдоров Англия представляла собой одну из ведущих морских держав. Ее способность бросить вызов и противостоять крупнейшей колониальной империи опиралась на мощные военно-морские силы, являвшиеся значительным фрактором в международных отношениях конца XVI в.

Военно-морская история тюдоровской эпохи традиционно вызывает интерес исследователей. Не осталось без внимания историков и каперство, преимущественно исследуемое как самостоятельное явление, в отрыве от истории королевского флота. Таким образом, вопрос о роли частных морских сил в англо-испанской войне, их взаимодействии с фрлотом по-прежнему актуален.

Генрих VIII Тюдор за короткий срок создал передовой мощный фрлот, превратив его из «события» феодальной эпохи в постоянно действующий государственный институт, показавший свою жизнеспособность даже в условиях частичной дезорганизации государственной власти середины века. На протяжении правления Эдуарда VI и Марии Тюдор этот фрлот позволял короне не зависеть в военном отношении от сил подданных, которые представляли лишь вспомогательный контингент. Но цена, которую платила корона за свое независимое положение, была высока, содержание «любимого детища Тюдоров» было чрезмерно затратным и шло второй строкой в королевском бюджете.
В правление Елизаветы Тюдор с началом англо-испанской войны расходы на фрлот превратились в неподъемную ношу для истощенной королевской казны. Это неизбежно привело к изменению положения военно-морских сил и к изменению отношения к ним со стороны государственной власти. Если во времена Генриха VIII, Эдуарда VI и Марии Тюдор стратегия и тактика действий на море в любых условиях оставались прерогативой короны, то начиная с 1580-х гг. частные силы постепенно перехватывают инициативу. В новых условиях королева была вынуждена играть роль хоть и привилегированного, но партнера. Королевская власть с утратой контроля над частными военно-морскими силами частично теряет и монополию на определение стратегии и тактики морской войны. Отныне именно частники становятся двигателем войны, корона же превращается в одного из главных поставщиков военно-морских ресурсов, извлекающего из сложившегося положения финансовую и стратегическую выгоду. Впрочем, такое «сотрудничество» государства и частных сил вполне решало задачи, стоящие перед Англией.

В данной статье рассмотрена частная военно-морская инициатива в качестве двигателя англо-испанской войны 1585-1603 гг.

Ключевые слова: Англия, Тюдоры, английский фрлот, каперство, англо-испанская война.

S. N. Gavrilov

\section{RIGHTFUL WAR BY THE HANDS OF PRIVATE OWNER: "PRIVATIZATION" OF NAVAL ACTIONS IN ENGLAND OF 1585-1603}

By the end of the Tudor rule, England was one of the leading maritime powers. Its ability to challenge and oppose the largest colonial empire rested on powerful naval forces, which were a significant factor in international relations at the end of the 16th century.

The naval history of the Tudor period traditionally attracts interest of researchers. Privateering is also an object of interest, but previously it was primarily explored as an independent phenomenon, in isolation from the history of the Royal Navy. Thus, the issue of the role of private naval forces in the Anglo-Spanish war, their cooperation with the Navy remains relevant.

Henry VIII Tudor, in short time, created a powerful navy, turning it from an "event" of the feudal epoch into a permanent state institution that showed its viability even under conditions of partial disorganization of state power in the middle of the century. This English navy was very advanced by the standards of the early Modern times. During the reign of Edward VI and Maria Tudor, the navy allowed the 
Crown to be militarily independent of the forces of its subjects, which now represented only an auxiliary contingent. However, the price paid by the crown for this independent position was very high, since the maintenance of the "beloved child of the Tudors" was excessively expensive and always ranked second in the state budget.

In the reign of Elizabeth Tudor, since the beginning of the Anglo-Spanish war, the cost of the navy turned into an unbearable burden for the almost empty royal treasury. This inevitably led to a change in the position of the naval forces and to a change in the perception of royal navy by government. While in the time of Henry VIII, Edward VI and Maria Tudor, the strategy and tactics of maritime actions in any conditions remained the prerogative of the crown, then since the 1580s onwards, private forces are

Эпоха правления Елизаветы Тюдор - время выхода англичан на океанские просторы. Сломив сопротивление мощных иберийских держав, Англия отстояла свое право на открытые воды, и, благодаря победе, заложила первый камень в строительство будущей Британской империи.

Несмотря на традиционный неутихающий интерес к различным аспектам военно-морской истории елизаветинской эпохи, вопрос о роли частных морских сил в войне с Испанией, особенно в последние годы XVI столетия, т.е. на этапе открытого конфликта, по-прежнему открыт для исследований.

Англия 1560-х гг. стала очевидцем постепенного изменения вектора внешней политики. Вспыхнувшая во Франции война между католиками и гугенотами в 1560-х гг. заметно ослабила эту страну, выступавшую на протяжении первой половины века в качестве основного противника. Отныне, она, увязшая во внутренних междоусобицах, не представляла для Англии серьезного соперника, а ее когда-то довольно сильный флот, бывший вполне достойным соперником англичанам на море, постепенно перестал рассматриваться как угроза. В конечном итоге, как и следовало ожидать, Испания, ранее воспринимавшаяся как противовес Франции, с восшествием на престол Елизаветы Тюдор постепенно возводилась в ранг основного врага. Жители Туманного Альбиона и так не питали дружеских чувств к Испании, теперь же эта нелюбовь все чаще подогревалась и оправдывалась пока еще очень осторожным, но со временем все более открыто проявляемым антииспанским политическим курсом правительства. gradually intercepting the initiative. Under the new conditions, the queen was forced to play the role of a privileged, but partner. The royal power, with the loss of control over private naval forces, is also losing its monopoly on the development of a strategy and tactics of the naval war. Henceforth those were the private owners who became the engine of war, the crown turned into one of the main suppliers of naval resources, primarily royal ships. Elizabeth had financial and strategic benefits from the current situation. However, such "cooperation" between the state and private forces completely solved the problems facing England.

This article deals with the private naval initiative as the engine of the Anglo-Spanish War of 1585-1603.

Key words: England, the Tudors, the English fleet, privateering, the Anglo-Spanish war.

К началу 1580-х гг. испанская угроза резко возросла. Гизы во Франции в 1578 г. получили испанские деньги, что подлило масло в огонь междоусобной войны с гугенотами и принесло Филиппу II уверенность, что у Франции еще долго будут связаны руки на внешнеполитической арене. Придавал сил испанскому монарху и успех нового командующего герцога Пармы, усмирявшего восставших в Нидерландах огнем и мечом. Присоединив к своим владениям Португалию, Филипп вместе с ней получил и португальские военные галеоны. Для английского правительства сложившаяся ситуация осложнялась восстанием Десмонда против правления англичан в Ирландии и попыткой вмешательства в этот конфрликт Испании. Учитывая все это, а также чрезвычайно успешное плавание Фрэнсиса Дрейка, ставшее своеобразной пощечиной Филиппу II, уже не оставалось никаких сомнений в скоро грядущем англо-испанском столкновении.

В Англии не было секретом то, что источник могущества Испании лежит в ее колониальных владениях. Поэтому в основе стратегии борьбы с ней лежало нанесение удара по коммуникациям, связывающим Иберийский полуостров и Америку. К разработке стратегических планов войны привлекались признанные эксперты, получившие богатый опыт дальних плаваний и сражений против испанцев в открытых морях. Сэр Хэмфри Джилберт, один из «морских псов» Елизаветы, в своем трактате 1577 г. под говорящим названием «Как Ее Величество может навредить королю Испании» писал: «Затронув его в Вест-Индиях, Вы повредите его глазное яблоко; заполучив его сокровища, почти полностью поступающие из Вест-Индий и 
являющиеся нервом войны, Вы принудите его распустить войско. Его планы потерпят крах, сила и мощь ослабнут, гордость будет растоптана, тирания же его будет совершенно уничтожена» [22, р. 170].

Однако осуществление этой стратегии наталкивалось на неразрешимые проблемы.

Ресурсы Испании и Англии были несоизмеримы. Филипп II в течение 1570-х гг. только серебра из Америки получил на сумму в 12 млн испанских дукатов (3 млн 300 тысяч английских фунтов). В следующие десять лет он получил серебра на 18,7 млн дукатов, а за последнее десятилетие века его казна пополнилась на 25 млн дукатов. Американское серебро было лишь малой долей в общем объеме доходов короны, большую часть которых составляли поступающие из-за рубежа налоги [23, р. 248]. Ежегодный же доход Елизаветы, например, в 1585 г. составлял около 300 тысяч фунтов, поэтому открытая война являлась непозволительной роскошью для английской казны [11, р. 55]. Английский военно-морской фолот, в ходе реформ Генриха VIII превратившийся в государственный институт, представлял собой грозную силу. Но хотя по степени организации он заметно и превосходил испанский, действие его кораблей за пределами проливов, особенно в Атлантике, в военное время грозили стать неподъемной ношей. Подавляющее большинство населения страны с восторгом встречало каждую новую антииспанскую акцию, но не горело желанием оплачивать эти дорогостоящие действия из своих кошельков. Не удивительно, что сборы дополнительных денег на фрлот и оборону вызывали отчаянные протесты [2, c. 139-147].

Акты Тайного совета этого времени дают нам многочисленные свидетельства того, что от платежей и служб уклонялись не только «большинство лондонских докторов права, джентльменов и других людей с хорошим достатком» [3, р. 44-45, 361, 477], но и жители иных графств [4, р. 602].

В последнее десятилетие века выразителем этого общего протеста против субсидий королеве станет парламентская оппозиция, рассматривавшая себя в качестве защитника национальных интересов. Причем сопротивление в парламенте будет нарастать с каждым годом. Тройная субсидия 1593 г. принесет в казну 636500 фунтов, сумму довольно внушительную, но всего четыре года спустя такая же субсидия даст лишь 160000 фунтов [11, р. 94].

Финансовые проблемы конца века подтачивали возможность реализации большой во- енно-морской кампании. Впрочем, проблемы, связанные с нехваткой денежных средств, начались задолго до начала открытой фазы англо-испанской войны. Даже во времена Генриха VII обеспечение матросами нескольких десятков кораблей королевского фрлота время от времени сталкивалось с трудностями [1, c. 59]. В елизаветинскую же эпоху нехватка матросов и управляющих кораблей постепенно превратилась в хроническую болезнь флота. Ни повышение жалованья, ни увеличение привилегий [9, р. 46-47], ни драконовские меры, обещавшие смерть за уход со службы без специального разрешения [27, р. 84-85], не могли исправить эту тяжелую ситуацию.

Причиной этого был отнюдь не рост количества кораблей. Флот Генриха VIII в количественном отношении существенно превосходил фрлот его дочери [13, р. 301-307; 20, p. 49-51, 120-121]. Да и количество мужчин, годных к морской службе, за 1560-1682 гг. возросло двукратно [20, р. 118]. Так что единственной причиной сложившейся ситуации являлась непопулярность службы.

Условия службы на кораблях королевского фрлота были действительно тяжелы даже по меркам того времени. «Ни один человек, имеющий иную профессию, не проводит свою жизнь в такой огромной и продолжительной опасности..., и... их (опасностей) так много, что лишь немногие здесь доживают до седин» [24, p. 351-367], - пишет современник. Вряд ли стоит удивляться многочисленным свидетельствам открытого неподчинения, дезертирства и даже восстаний на фрлоте. Весьма точную характеристику матросов дал Ричард Хоукинс, сравнивший их с неуправляемыми лошадьми, «которые, закусив узду, принуждают наездника подчиниться своей воле» [24, р. 351-367].

Интересно, что частники обычно не испытывали подобных проблем, хотя условия службы на их кораблях были гораздо тяжелее. В целях экономии они отправляли в плавания корабли без врачей. Уровень смертности, особенно в продолжительных экспедициях, часто достигал 50 процентов. По подсчетам Ф. Дайера, за последние 12 лет XVI в. от болезней умерло не менее 10000 моряков [12, р. 135]. Но риск потерять свою жизнь не останавливал желающих, ведь участие в экспедиции могло принести большие деньги. Да и рассказы о баснословно богатых моряках, ушедших в море в долгах, а вернувшихся богатыми как восточные владыки, были весьма популярны в английском обществе. Так что привлекательность службы в королевском фрлоте на этом фроне явно про- 
игрывала. Причем проблема набора матросов проявилась уже в середине столетия. В 1558 г. Елизавета была вынуждена запретить проведение любых частных экспедиций, поскольку «немалое число самых лучших и способных кораблестроителей, матросов, канониров, мореплавателей и лодочников, несмотря на обязанность послушания, которое должны проявлять добрые подданные, бегут со службы Ее Величества и любыми средствами нанимаются на корабли, покидающие королевство и уходящие в торговые экспедиции, а также в поисках наживы» [27, р. 89-90].

Так что именно в финансовой сфере кроется причина того, что люди предпочитали участие в частных предприятиях. В основном матрос королевского корабля мог рассчитывать лишь на жалованье. В 1582 г. оно составляло всего 10 шиллингов в месяц [19; 23, р. 500-501]. Эта скромная сумма, учитывая инфляцию, не превышала те 6 шиллингов и 8 пенсов, что платились за службу в 1546 г.

Судить о размерах жалованья на частном торговом судне довольно трудно. Оно сильно зависело от многих переменных и, в первую очередь, от статуса экспедиции, ее цели, времени проведения, направления и протяженности. Не последнюю роль играла щедрость инвесторов. Большое значение имело также и то, что матросам не возбранялось самостоятельно заниматься коммерцией [8, р. 234-246]. Доход завербовавшегося на купеческое судно мог в разы превосходить жалованье матроса королевского корабля. Не менее привлекательны были и каперские суда. При захвате приза стоимостью в 2000 фунтов каждому в команде из 50 человек причиталось по 4 фунта. Да и месячное жалованье здесь обычно составляло 8-12 фунтов. Но гораздо больший доход могло дать мародерство на верхней палубе, которое рассматривалось как вполне законное действие, ибо гарантировалось обычным правом. Пожалуй, одним из ярких примеров можно считать разграбление в 1592 г. знаменитого португальского каррака «Madre de Deus», захваченного вблизи Азорских островов большой эскадрой, включающей корабли королевы, графа Кумберленда, Уолтера Рэли, Джона Хоукинса и купцов Сити. Предварительный подсчет обещал весьма большой барыш акционерам, ведь стоимость приза была бегло оценена в 500000 фунтов. Но ночью английские матросы успели разграбить судно, так что акционерам досталось лишь около 140000 фунтов [16, р. 105118; 25, р. 269-276]. Служба в королевском фрлоте не могла дать возможность такого обо- гащения. По словам Джона Хоукинса, казначея флота, корабли не в состоянии сохранить свои команды, «ведь оплата так низка» [14, р. 33; 24, p. 354].

Высокая стоимость действий королевского флота вынуждала знающую цену деньгам королеву искать помощи подданных. Наполовину частные, наполовину государственные акционерные предприятия превратились в символ эпохи. Среди их участников была как сама Елизавета, так и фрлотские офицеры, должностные лица и частные предприниматели. Учитывая факт участия королевских кораблей, некоторые исследователи настаивают на выделении подобных полуофициальных предприятий из числа каперских, поскольку они всецело не финансировались частными лицами и играли роль национальных, в которых интересы королевы преобладали [5, р. 5; 6, р. 36]. Впрочем, не стоит преувеличивать это отличие, ведь если мы считаем, что война с Испанией соответствовала английским национальным интересам, то мы не можем отрицать и того, что и активность каперов была в национальных интересах. Да и в реальности инструкции Елизаветы не имели большой силы.

Практика акционерных кампаний стала распространяться уже в 1560-х гг. К 1561 г. относится первое документально зафиксированное участие Елизаветы в подобном предприятии. Купцу Уильяму Честеру, намеревающемуся направиться к африканскому побережью, было выделено четыре корабля и 500 фрунтов. Вклад королевы составил треть от капитала экспедиции [18]. В 1580-е гг. практика участия Елизаветы уже была поставлена на постоянную основу. Например, в знаменитом рейде Дрейка к Вест-Индиям 1585 г. участвовали королевские «Aid» и «Elizabeth Bonaventure», оцененные в 10000 фунтов. Предприятие получило еще и денежный вклад королевы в 10000 фунтов [21, p. XIII]. В Кадисской экспедиции 1587 г. вклад Елизаветы состоял из четырех кораблей и двух пинас. Другими участниками в этом предприятии были Дрейк, лорд-адмирал Чарльз Говард, представители купеческого сообщества Лондона и члены Левантийской компании. Совместное инвестирование, впрочем, как и любая иная форма предприятия, было связано с риском. Но благодаря более широкой возможности привлечения средств такие предприятия в случае успеха обещали многократную прибыль, так что они оставались весьма привлекательными для королевы, которая, учитывая ее положение привилегированного соинвестора, всегда претендовала на солидную при- 
быль даже там, где остальные участники довольствовались малым. Например, не очень прибыльная Вест-индская экспедиция 1585 г. принесла участникам лишь по 5 шиллингов на вложенный фунт, Елизавета же получила 20000 фунтов в качестве дивидендов и, помимо этого, еще 2000 фунтов за использование королевских кораблей.

В елизаветинское время многие знатные люди предпочитали «морскую охоту» иным занятиям. Наиболее видным представителем слоя нобилитета и джентльменов, бросивших себя в горнило войны с Испанией, был графр Кумберленд. Он часто завершал экспедиции триумфально, но его большие затратные предприятия фринансово были убыточны. По его собственным словам, он «утопил все свои земли в море» [5, р. 79].

Активно поощрялись к участию в организации морских предприятий и люди более низких социальных слоев. Они охотно занимались каперством и, таким образом, выполняли работу военно-морского фрлота. Согласно подсчетам К. Эндрюса, Суд Адмиралтейства только с июля 1585 г. по март 1586 г. выдал 88 каперских писем-репрессалий. К этой цифре нужно также прибавить и те письма-патенты, что выдавались лордом-адмиралом и самой королевой [5, р. 33]. Страну охватила самая настоящая «каперская лихорадка». В 1589-1591 гг. только известных нам каперских судов насчитывалось 236, но и эта цифра далеко не полная [5, р. 32].

Доход от деятельности частников являлся весьма важным источником пополнения королевской казны. Юлий Цезарь, судья Суда Адмиралтейства, в 1590 г. сообщал лорду Говарду: «Со времени начала выдачи репрессалий Ее Величество получила более 200000 фунтов, т.е. около 40000 фунтов в год, что составило не менее двух третей стоимости действий флота» [7].

Выдача каперских свидетельств приобрела большой размах, ведь каперство давало возможность чужими руками вести затратную войну, не втягивая в нее государство. Горячий поборник развития частной инициативы сэр Джордж Кэри, губернатор острова Уайт, настаивая на необходимости выдачи свидетельств всем желающим, в письме к государственному секретарю Уолсингему в 1587 г. аргументировал: «У Ее величества нет нужды замечать недостатки тех, кто готов ей служить» [21, р. 3336]. Выдавая мирное время свидетельства, королева «даст возможность своим подданным восполнять их потери и приобрести сверх этого, и, помимо всего, она получит возможность досадить королю (Испании), не принимая участия в этом» [21, р. 33-36].

Ставка на частников действительно помогала отсрочить вступление государства в войну, ведь выдача свидетельств была вполне законной. В основе этой практики, получившей широкое распространение в Средневековье, лежало обычное право. Официально они выдавались только тем, кому в море был нанесен ущерб. Именно в этом контексте в Англии и рассматривали Вест-индскую экспедицию 1585 г. Дрейк получил официальный приказ проследовать в испанские порты и освободить английские корабли [21, р. XIII], задержанные во время испанского эмбарго. О тайных поручениях остается лишь догадываться. Такая тактика позволила Елизавете в ответ на все упреки и угрозы Филиппа II заявить, что Дрейк превысил свои полномочия, а поэтому ее вины нет. Испанскому монарху, вряд ли поверившему заверениям королевы, не осталось ничего иного, как признать, что повода к войне действительно нет, ведь Дрейк не имел официальных инструкций идти к Вест-Индиям.

Осознавая военную, политическую и экономическую выгоду от быстро растущей частной активности, правительство поощряет строительство частных судов. В 1582 г. в стране было двадцать купеческих кораблей свыше 200 тонн, в следующие пятнадцать лет семьдесят два было построено, и этот кораблестроительный бум продолжался до конца войны. Рост торгового фрлота оказывал неизгладимое впечатление. В своем сочинении «Государство Англия в год 1600 от Рождества Христова» Томас Уилсон с гордостью за страну повествует: «Весь фрлот королевы состоит из небольшого количества (кораблей), и это может удивить, так как она, как всем известно, имеет такую силу в море, что ни один государь не способен противостоять ей. Но причина этому ясна, и состоит она в том, что этот флот, будучи великой силой, не составляет и двадцатую часть всей мощи Англии, ведь здесь только одной Темзе приписано 2000 кораблей, и даже самые худшие из них вполне годны для службы, как военной, так и купеческой...» [31, р. 36-37].

Следствием расцвета частной инициативы на море и постепенного снижения самостоятельных действий королевского фрлота стала потеря монополии государства на разработку стратегии войны с Испанией. Елизавета все чаще просит совет тех, кто стоит во главе частных сил. Весьма показательна в этом отношении речь Дрэйка, произнесенная им во время кругосветной экспедиции 1577-1580 гг. перед 
офицерами и матросами. Он поведал, что во время тайной встречи королева сказала ему, что за нанесенные обиды она хочет отомстить королю Испании и в этом полагается на совет Дрейка как единственного человека, способного это сделать. Дрэйк ответил Ее Величеству, что «в самой Испании вряд ли можно что-то сделать, а лучшее место для нанесения удара испанцам - их Индии» [30, р. 94].

Таким образом, «приватизация» военных действий на море в последней трети XVI в. стала основной тенденцией развития военно-морских сил в Англии. Согласно оценке Дэвида Лоудза, «с 1585 г. по 1604 г. каперы покрывали 50 процентов усилий по ведению войны, что давало возможность стране со слабой финансовой инфраструктурой выстоять в одной из длиннейших войн в ее истории и противостоять государству, чьи ресурсы были во много раз превосходящими» [17, р. 127].

На сегодняшний день большинство исследователей не склонно оспаривать большую роль частных сил в англо-испанской войне. «Елизавете удалось разгромить Испанию минимальной ценой, т.е. основываясь, главным образом, на собственном фрлоте и каперах» [15, р. 342-343]. Но это порождает и другой вопрос. Действительно ли Елизавета и правительство осознано проводили такой курс? Или же опора на частные силы была следствием неспособности и невозможности обуздать и контролировать растущую частную инициативу?

Здесь вряд ли можно дать однозначный ответ. Как точно подметил Ч. Уилсон, Елизавета, прежде всего, была государыней, главная цель которой состояла в обеспечении безопасности страны [29, р. 6-7]. Елизавета Тюдор имела богатый опыт властвования. Более того, это был опыт выживания и властвования в кругу мужчин, которые, даже с учетом того, что XVI век это время правления многих действительно незаурядных женщин, были еще не готовы целиком и полностью подчиниться женщине. Обладавшая опытом и мудростью Елизавета понимала, что управление мужчинами во власти, многие из которых были также незаурядны, задача не только сложная, но и подчас невыполнимая. Так что не препятствовать деятельности каперов, и, по возможности, извлечь из этой деятельности финансовую и политическую прибыль - лучшее, что она могла сделать.

Впрочем, нам стоит обратить внимание и на то, что «приватизация» войны на море, помимо положительных результатов, имела для короны и государства также и негативные послед- ствия. Первые Тюдоры сохраняли монополию на определение стратегии войны и проведение военных действий на море, частные же корабли они использовали в качестве вспомогательного флота путем принудительной вербовки или найма. Елизавета утратила эту монополию, согласившись на роль привилегированного партнера. Более того, командующие считали для себя возможным игнорировать ее приказы. Они руководствовались, прежде всего, не понятием государственной необходимости, а интересами коммерческой прибыли.

Кампания 1589 г., возглавляемая Дрейком и сэром Джоном Норрисом, дает нам хороший пример того, как частные акционеры, ведомые жаждой наживы, подчас действовали вразрез с интересами правительства и королевы. Истощенная в предыдущий год подготовкой к отражению Непобедимой Армады казна не давала возможность полагаться на силы королевского фрлота в столь важный момент. Между тем, предоставлялся действительно удобный шанс уничтожить или захватить оставшиеся после краха Армады изрядно потрепанные корабли противника, сосредоточенные в Бискайском заливе. Именно это и видела Елизавета в качестве главной задачи кампании. Лишь после выполнения этой миссии допускалась возможность попытки перехвата Серебряного флота, который, как считали англичане, в этом году будет особенно ценным и беззащитным, ибо корабли из Охраны Индий были отозваны для участия в Армаде. Предполагалась и возможность высадки десанта в Португалии с целью помощи дону Антонио в занятии трона. Интересно, что Дрейк и Норрис заверили, что понимают государственные задачи и обещали повиноваться, однако, и это очевидно, они с самого начала не собирались этого делать [23, р. 273]. Вместо того, чтобы потратить недели на уничтожение остатков испанского флота в Бискайском заливе и, тем самым, подвергнуть риску получение финансовой прибыли, они предприняли попытку высадки в Португалии для помощи дону Антонио. Эта затея окончилась полным провалом, ветер также не позволил им развернуть эскадру к Азорским островам. Экспедиция принесла убытки, шанс уничтожить испанский фллот был утерян, и это тем более было плачевно, поскольку Филипп II именно в это время приступил к строительству современного фрлота и его администрации, частично копируя английские образцы [26, р. 33, 40, 192-193; 23, р. 279].

В словах королевы, обращенных к Дрейку и Норрису, ощущается обида и горечь: «Перед 
вашим отъездом вы в не раз клятвенно обещали, уверяя нас и кое-кого из нашего Совета, что вашим первым и главным действием будет захват и нейтрализация военного флота и кораблей короля Испании в портах их нахождения; если же вы этого не сделаете, заверяли вы, вы согласитесь считаться предателями» [28, р. 99]. Но обычно командующие в подобных случаях избегали наказания. Мудрая королева отлично понимала расклад сил. Испытывая фринансовые затруднения, она была вынуждена позволять служащим использовать служебное положение в личных интересах.

Жажда наживы и славы стала двигателем англо-испанской войны. Эта жажда охватила всех, начиная от мелкого торговца и заканчивая самой королевой. Не обошла она стороной и офицеров военно-морской администрации. Личные интересы в их среде присутствовали всегда, но теперь они все чаще выходят на первый план, внося разлад в единство действий Совета. В то время как ранее офицеры стремились четко выполнять задачу по обеспечению эффрективной работы королевского военно-морского флота, используя для этого частные ресурсы, теперь же они все чаще воспринимают себя в качестве представителей частных сил, в интересах которых они используют королевские корабли и всю систему поддержки фллота.
Впрочем, новые реалии отнюдь не умаляли значение королевского флота, который вполне успешно выполнял свои основные задачи по обороне государства [10, р. 249]. Если амбиции создания океанской империи и существовали, их воплощение в то время было невозможно. Главным приоритетом оставалась задача выживания [23, р. 197]. Статистические данные по расходным статьям королевского фрлота за период с 1588 г. и до конца правления Елизаветы свидетельствуют, что он оставался объектом пристального внимания. Можно без преувеличения сказать, что и выполнение оборонительных задач королевскими военно-морскими силами, находящимися в полной боеготовности, было возможным благодаря тому, что частники с успехом справлялись с задачей подрыва могущества Испании на океанских просторах.

Таким образом, говоря о роли частных военно-морских сил в англо-испанской войне, можно констатировать, что эти силы не просто помогли отстоять независимость страны и одержать победу, они, развязавшие частную войну на море, стали основным средством достижения целей государственной политики. Проявившая же мудрость Елизавета стремилась не вставать на пути этой малоуправляемой частной инициативы.

\section{Источники и литература / References}

1. Гаврилов С. Н. Английский фрлот эпохи Тюдоров как государственный институт. Ростов-на-Дону: Издательство ЮФУ, 2014. 204 c.

Gavrilov S. N. Angliyskiy flot epokhi Tyudorov kak gosudarstvennyy institute (The English Navy of the Tudor period as a state institution). Rostov-na-Donu: SFU publ., 2014. 204 p. (In Russian).

2. Дмитриева О. В. Социально-политическая борьба в Англии в конце XVI - начале XVII в.: рукопись диссертации канд. ист. наук. М.: МГУ, 1985. 262 с.

Dmitriyeva O. V. Sotsial'no-politicheskaya bor'ba v Anglii v kontse XVI - nachale XVII v. (Socio-political struggle in England in the late XVI - early XVII century): thesis. Moscow: MSU publ., 1985. 262 p. (In Russian).

3. Acts of the Privy Council / ed. by J. R. Dasent. L.: Her Majesty's Stationery Office, 1901. Vol. 24. 537 p.

4. Acts of the Privy Council / ed. by J. R. Dasent. L.: Her Majesty's Stationery Office, 1905. Vol. 29. 812 p.

5. Andrews K. R. Elizabethan Privateering during the Spanish War, 1585-1603. Cambridge: Cambridge University Press, 1964. 297 p.

6. Bevan B. The Great Seamen of Elizabeth I. L., 1971.

7. British Library. Lansdowne MS. 157. f. 434.

8. Brooks F. W. A Wage-scale for seamen, 1546 // English Historical Review. 1945. Vol. 60. P. 234-246.

9. Collection of Admiralty Statutes, 1274-1741. L., 1755.

10. Crowson P. S. Tudor Foreign Policy. L.: Palgrave Macmillan, 1973. 302 p.

11. Dietz F. English Public Finance. L.: Frank Cass \& Co Ltd, 1964. Vol. II. 478 p.

12. Dyer F. E. The Elizabethan Sailorman // Mariner's Mirror. 1924. Vol. 10. №. 2. P. 133-146.

13. Glasgow T. List of Ships of the Royal Navy from 1539 to 1588 - the Navy from its infancy to the defeat of the Spanish Armada // Mariner's Mirror. 1970. Vol. 56. P. 299-307.

14. The Great Enterprise. The history of the Spanish Armada as revealed in contemporary documents / ed. by Usherwood S. L.: Folio Society, 1978. 194 p.

15. Guy J. Tudor's England. Oxford: Oxford University Press, 1988. 582 p.

16. Hakluyt R. The Principal Navigations, Voyages, Traffiques and Discoveries of the English Nation. L.: J.M. Dent, 1907. Vol. VII.

17. Loades D. England's Maritime Empire: seapower, commerce and policy 1490 - 1690. Singapore: Longman Pub Group, 2000. 277 p. 
18. The National Archives. State Papers. 12/26/43.

19. The National Archives. State Papers. 12/186/43.

20. Oppenheim M. A history of the Administration of the Royal Navy. L., N.Y.: John Lane, 1896. 444 p.

21. Papers relating to the Navy during the Spanish War, 1585-1587 / ed. by J.S Corbett. L.: Navy Record Society, 1898. $363 \mathrm{p}$.

22. Quinn D. B. The Voyages and Colonizing Enterprises of Sir H. Gilbert. L.: Hakluyt Society, 1940. Vol. I. 238 p.

23. Rodger N. A. M. The Safeguard of the Sea. A Naval history of Britain, 660-1649. L.: Penguin Books, 2004. 691 p.

24. Scammell G. V. The Sinews of War: manning and provisioning English fighting ships c. 1550 - 1650 // Mariner's Mirror. 1987. Vol. 73. N. 4. P. 351-367.

25. Sir William Monson's Naval Tracts / ed. by M. Oppenheim., L.: Navy Record Society, 1902. Vol. I. 395 p.

26. Thompson I. A. A. War and Government in Habsburg Spain, 1560-1620. L.: Athlone Press, 1976. 374 p.

27. Tudor Royal Proclamations: The later Tudors (1553-1587) / ed. by Hughes P.F., Larkin J.L. Yale.: Yale University Press, 1969. Vol. II. 548 p.

28. Wernham R. B. After the Armada: Elizabethan England and the struggle for Western Europe. Oxford.: Oxford University Press, 1984. $613 \mathrm{p}$.

29. Wilson Ch. Queen Elizabeth and Revolt of Netherlands. L.; Macmillan, 1970. 168 p.

30. Wilson D. The World Encompassed. Drake's Great Voyage 1577-1580. L.: Allison \& Busby, 1998. 256 p.

31. Wilson T. The State of England, Anno Dom. 1600 / ed. by F.J. Fisher. L.: Camden Society, 1936. 54 p. 